\title{
Quality of Life after Epilepsy Surgery in Korea
}

\author{
Smi Choi-Kwon, PhD, RN ${ }^{\text {a }}$; Chun-Kee Chung, MD ${ }^{\text {b }}$ S Sang Kun Lee, MD'; \\ Jimi Choi, RNª; Kihye Han, RN, MSN ${ }^{a}$; Eun-Hyun Lee, PhD, RN ${ }^{d}$ \\ ${ }^{a}$ Research Institute of Nursing Science, College of Nursing, Seoul National University, Seoul, Korea \\ Departments of ${ }^{b}$ Neurosurgery and ${ }^{C}$ Neurology, Seoul National University Hospital, Seoul, Korea \\ 'Graduate School of Public Health, Ajou University, Suwon, Korea
}

$\begin{array}{ll}\text { Received } & \text { June 17, 2008 } \\ \text { Revised } & \text { August 19, 2008 } \\ \text { Accepted } & \text { August 19, 2008 }\end{array}$

\section{Correspondence}

Smi Choi-Kwon, $\mathrm{PhD}$, RN

Research Institute

of Nursing Science,

College of Nursing,

Seoul National University,

28 Yeongeon-dong, Jongno-gu,

Seoul 110-799, Korea

Tel $+82-2-740-8830$

Fax $+82-2-765-4103$

E-mail smi@snu.ac.kr
Background and Purpose Temporal changes in the quality of life (QOL) and the underlying factors after epilepsy surgery might be specific to Korea, where social stigma toward patients with epilepsy is still pronounced.

Methods The seizure characteristics, number of antiepileptic drugs (AEDs), and the presence of stigma, anxiety, and depression were assessed before and after surgery (at 6 months and around 2 years) in 32 surgery patients and 32 nonsurgery patients. The QOL was compared between these groups using the Epilepsy Surgery Inventory-55 questionnaire. The factors affecting QOL were also evaluated.

Results The scores in the mental, physical, and role-functioning domains were significantly higher at 6 months (all $p<0.01)$ and around 2 years (all $p<0.01)$ than at baseline in the surgery group but not in the nonsurgery group. The factors related to QOL differed at the two followup times, with seizure freedom being important at 6 months, and AEDs and depression being important at around 2 years.

Conclusions A marked increase in QOL in our population was observed after epilepsy surgery. Although the small sample limits the interpretation of the results, the QOL change in our surgery patients shows similar trends to those reported in Western countries. A full understanding of underlying factors related to QOL might aid the development of optimal strategies for improving the long-term postsurgery QOL in this population.

J Clin Neurol 2008;4:116-122

KEY WORDS Epilepsy surgery, Quality of life, Epilepsy Surgery Inventory-55, Anxiety, Depression, Stigma.

\section{Introduction}

Epilepsy is one of the most common chronic neurological disorders. Although recent advances in surgical techniques mean that intractable epileptic seizures can be managed relatively well, some studies have inferred that a reduction in seizures does not necessarily lead to an improvement in quality of life (QOL), ${ }^{1}$ while others have found that seizure freedom postsurgery is associated with significant improvements in QOL. ${ }^{2-8}$ The QOL can be complex and multifactorial, depending not only on the seizure outcome, but also on the patient's psychological status and feelings of social stigma.-11 The QOL of surgery patients in Asian countries, where the social and cultural environment can differ from their Western counterparts, has rarely been studied, ${ }^{12}$ nor have the factors affecting QOL in these patients been investigated at different follow-up times.

Therefore, this study was performed to determine the QOL of surgery patients and the factors related to QOL at 6 months and 2 years after surgery. We also compared the QOL in the surgery group with that in a nonsurgery control group comprising patients with a similar presurgery evaluation.

\section{Methods}

This study was approved by the Institutional Review Board of the College of Nursing at Seoul National University. We collected data before surgery and at 6 months and around 2 years (mean 23.4 months) after surgery in the surgery group. In the nonsurgery group, data were collected at 6 months and 
around 19 months (mean 19.3 months) after the initial assessment. Six months after surgery was chosen as the first follow-up time to avoid the compounding effect of surgery and to give the subjects sufficient time to adapt to their new lives. The second follow-up was at around 2 years after surgery in order to reveal the long-term effects of surgery on QOL. Written informed consent was obtained before each interview, with the first interview taking place in the Epilepsy Monitoring Unit (EMU) at Seoul National University Hospital.

Sixty-four patients with intractable seizure who were admitted to the EMU underwent presurgery evaluations including long-term monitoring. An extensive interview was also conducted to evaluate the presurgery QOL and the presence of depression, anxiety, and stigma. The intractable patients were defined as those who had experienced uncontrolled seizures for more than 2 years despite having received appropriate antiepileptic drug (AED) polytherapy for more than 2 years.

Among the 64 patients, those patients who underwent the same presurgery evaluation but no surgery constituted the control group $(n=32)$. They did not receive surgery for one of the following reasons: 1) they had an ictal onset zone that could not be localized $(n=9) ; 2)$ their ictal zone could be localized but was discordant with the results obtained from MRI, PET, or ictal Single Photon Emission Computed Tomography (SPECT) $(n=12) ; 3)$ they were treatable with AEDs despite having been referred from other hospitals as intractable cases $(n=3)$; or 4$)$ they refused surgery $(n=8)$. In accordance with Birbeck et al. reporting that a significant improvement in QOL requires seizure freedom, ${ }^{13}$ we chose the absence of seizures as the end point.

Before the interview, all the patients were assessed by experienced epileptologists at Seoul National University regarding the type, duration, and frequency of the seizures. The number of AEDs was also assessed. Seizure types were categorized into four groups: 1) simple partial seizures, including aura only; 2) complex partial seizures with alteration of consciousness; 3) generalized seizures; and 4) other types of seizure, including absence seizures and myoclonic seizures. The interview was performed by two trained research nurses using a structured questionnaire that gathered demographic data on age, gender, level of education, marital status, current employment status, and economic status. ${ }^{14}$

The Korean version of the Hospital Anxiety and Depression (HAD) scale comprising 14 items with 4-point responses (7 items each for anxiety and depression) was used to measure the depression and anxiety levels. ${ }^{15,16}$ Depression or anxiety was considered to be present if the score was $>10$ in either the anxiety or depression inventory, with scores of $8-$ 10 considered indicative of borderline depression or anxiety. ${ }^{15}$ In statistical comparisons, those patients with borderline de- pression or anxiety were categorized as having depression or anxiety.

A three-item epilepsy stigma scale was used, ${ }^{10,17}$ with each item scored as a simple yes (1) or no (0) response. The overall score was the sum of the positive responses (range, 0-3), with a higher score indicating a higher likelihood of the patient feeling stigmatized. For statistical analysis, those patients with nonzero scores were categorized as having stigma.

QOL was assessed using the Epilepsy Surgery Inventory (ESI)-55 questionnaire, which consists of 55 items. ${ }^{18}$ The ESI-55 is scored on 11 subscales (health, energy, QOL, social functioning, emotional functioning, cognitive functioning, role-emotional, role-memory, role-physical, physical function, and pain) and 3 composite scales for physical health, mental health, and role functioning. The questionnaire was translated into Korean by a professional translator. For the Short-Form Health Survey (SF)-36 items contained in the ESI-55, the official Korean translated version of the SF-36 (with known reliability and validity) was used. ${ }^{19,20}$ Testing of its reliability revealed that its internal consistency (Cronbach's alpha) ranged from 0.78 to 0.90 , which exceeds the generally accepted criterion (0.70) for adequate reliability for group comparisons. Test-retest reliabilities at baseline and 6 months in the control group ranged from $r=0.79$ to $r=0.84$, which also exceeds the commonly used cutoff of $r=0.70$.

During the clinic visits at each follow-up after the initial assessment, the changes in seizure characteristics (including seizure frequency and number of AEDs) were recorded by an epileptologist. The scores on the ESI-55, HAD, and stigma scales were also obtained for both groups.

\section{Statistics}

The data were analyzed with descriptive statistics, chisquare test, and paired $t$-test for demographics and clinical characteristics of the subjects. ANOVA or paired $t$-test was also used for comparing QOL and the factors related to QOL between the groups and between the differenttime points in each group.

\section{Results}

\section{Demographic and clinical characteristics of the subjects}

Fig. 1 shows the number of patients included in each part of the protocol. Of the 32 patients who received surgery, 3 could not be contacted, leaving 29 patients at the 6-month follow-up. At the 2-year follow-up, 2 could not be contacted, 1 had died, and 1 had developed schizophrenia, leaving 25 patients. Of the 32 patients who did not receive surgery, 4 could not be contacted, 2 had moved to another country, and 


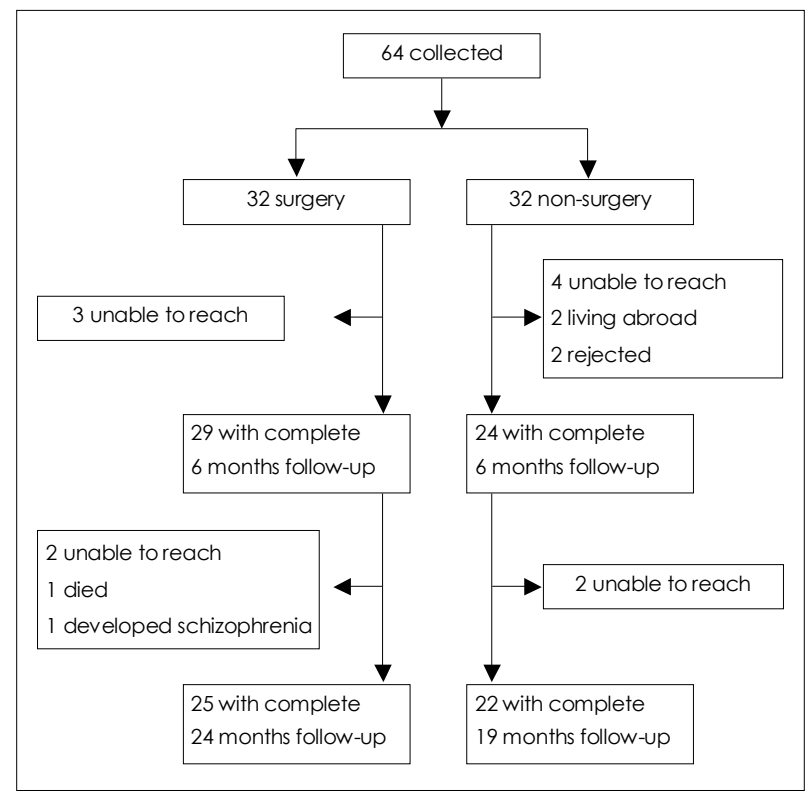

Fig. 1. Flow diagram.

2 declined to participate in the study, leaving 24 patients at the 6-month follow-up. At the 19-month follow-up, 2 could not be reached, leaving 22 patients in the nonsurgery group.

At the baseline, the demographic and clinical characteristics did not differ between the surgery and nonsurgery groups except for the diagnosis and the type of seizure (Table 1$)$. Anterior temporal-lobe resection was performed in $22(69 \%)$ of the surgery patients, and $10(31 \%)$ received neocortical resection.

Of the 29 patients who had received surgery, $25(86 \%)$ were seizure-free, $3(10 \%)$ had one seizure per month, and $1(3 \%)$ had four seizures per month at the 6-month follow-up. At the 2-year follow-up, 21 (84\%) were seizure-free, and $2(8 \%)$ and $2(8 \%)$ had reductions in seizure frequencies of $\geq 75 \%$ and $<75 \%$, respectively. Relapse at around the 2-year followup occurred in two patients $(8 \%)$ who remitted at 6 months after surgery.

Of the 24 patients who had not received surgery, 10 $(42 \%)$ achieved seizure freedom and $2(8 \%)$ had a reduction in seizure frequency of $>75 \%$ at the 6 -month followup. Of the 22 patients followed-up at 19 months, 10 (45\%) achieved seizure freedom (Table 2 ). Table 2 indicates that AED usage had decreased at around 2 years $(p<0.01)$ but not at 6 months after surgery, whereas AED usage had increased at around 19 months $(p<0.01)$ in the nonsurgery group.

\section{Stigma, anxiety, and depression}

At the baseline, the presence of stigma, anxiety, and depression did not differ significantly between the surgery and nonsurgery groups (Table 2). The number of patients with stigma, anxiety, or depression declined significantly (all $p<$ 0.01 ) between the baseline and at both follow-ups in the
Table 1. Demographics and clinical characteristics of patients with epilepsy

\begin{tabular}{|c|c|c|}
\hline & $\begin{array}{l}\text { Surgery } \\
\text { group } \\
(n=32) \\
\end{array}$ & $\begin{array}{c}\text { Nonsurgery } \\
\text { group } \\
(n=32)\end{array}$ \\
\hline Age (years) & $30.6 \pm 9.9$ & $31.4 \pm 9.3$ \\
\hline \multicolumn{3}{|l|}{ Gender } \\
\hline Male & $19(59.4)$ & $26(81.3)$ \\
\hline Education (years) & $12.8 \pm 2.8$ & $13.6 \pm 2.9$ \\
\hline \multicolumn{3}{|l|}{ Marital status } \\
\hline Married & $20(62.5)$ & $21(65.6)$ \\
\hline Single & $12(37.5)$ & $11(34.4)$ \\
\hline \multicolumn{3}{|l|}{ Diagnosis } \\
\hline TLE & $25(78.1)$ & $12(37.5)^{* *}$ \\
\hline FLE & $2(6.3)$ & $8(25.0)$ \\
\hline PLE & $1(3.1)$ & $2(6.3)$ \\
\hline OLE & $2(6.3)$ & $0(0)$ \\
\hline Other & $2(6.3)$ & $10(31.3)$ \\
\hline \multicolumn{3}{|l|}{ No. of AEDs } \\
\hline 0 & $0(0)$ & $2(6.3)$ \\
\hline 1 & $11(34.4)$ & $10(32.3)$ \\
\hline 2 & $5(15.6)$ & $9(28.1)$ \\
\hline$>2$ & $16(50.0)$ & $11(34.4)$ \\
\hline \multicolumn{3}{|l|}{ Employed } \\
\hline Yes & $18(56.3)$ & $22(68.8)$ \\
\hline \multicolumn{3}{|l|}{$\begin{array}{l}\text { Economic status (monthly } \\
\text { income, South Korean won) }\end{array}$} \\
\hline$<100$ million & $11(34.4)$ & $11(34.4)$ \\
\hline 100-200 million & $15(46.9)$ & $9(28.1)$ \\
\hline$>200$ million & $6(18.8)$ & $12(37.5)$ \\
\hline Duration of seizures (years) & $14.7 \pm 11.4$ & $10.1 \pm 8.4$ \\
\hline \multicolumn{3}{|l|}{ Type of seizure } \\
\hline Simple partial & $1(3.1)$ & $3(9.4)^{*}$ \\
\hline Complex partial & $26(81.3)$ & $20(62.5)$ \\
\hline Secondary generalized & $5(15.6)$ & $9(28.1)$ \\
\hline \multicolumn{3}{|l|}{ Seizure frequency } \\
\hline$\leq 1 /$ month & $15(46.9)$ & $14(45.8)$ \\
\hline$>1 /$ month & $17(53.1)$ & $18(54.2)$ \\
\hline
\end{tabular}

Data are mean \pm SD or $n(\%)$ values. ${ }^{*} p<0.05,{ }^{*} p<0.01$. SD: standard deviation, AEDs: antiepileptic drugs, TLE: temporallobe epilepsy, FLE: frontal-lobe epilepsy, PLE: parietal-lobe epilepsy, OLE: occipital-lobe epilepsy

surgery group but not in the nonsurgery group. Moreover, the number of patients with stigma, anxiety, or depression was significantly lower in the surgery group than in the nonsurgery group at follow-ups at 6 months $(p<0.05)$ and around 2 years $(p<0.01)($ Table 2$)$.

\section{Quality of life in the surgery and nonsurgery patients}

The QOL scores on the 11 subscales and 3 composite scales of the ESI-55 at different follow-ups are listed in Table 3. 
Table 2. Changes in seizure frequency, stigma, anxiety, and depression

\begin{tabular}{|c|c|c|c|c|c|c|c|}
\hline & & \multicolumn{3}{|c|}{ Surgery group } & \multicolumn{3}{|c|}{ Nonsurgery group } \\
\hline & & $\begin{array}{c}\text { Baseline } \\
(n=32)\end{array}$ & $\begin{array}{l}6 \text { months } \\
(n=29)\end{array}$ & $\begin{array}{l}2 \text { years } \\
(n=25)\end{array}$ & $\begin{array}{c}\text { Baseline } \\
(n=32)\end{array}$ & $\begin{array}{l}6 \text { months } \\
(n=24)\end{array}$ & $\begin{array}{c}19 \text { months } \\
(n=22)\end{array}$ \\
\hline \multicolumn{2}{|c|}{$\begin{array}{l}\text { Seizure frequency } \\
\text { reduced by } \geq 75 \%\end{array}$} & & $25(86.2)^{\ddagger}$ & $23(92.0)^{\ddagger}$ & & $12(50.0)$ & $10(45.4)$ \\
\hline \multicolumn{2}{|c|}{ Seizure freedom } & & $25(86.2)^{\ddagger}$ & $21(84.0)^{\ddagger}$ & & $10(41.7)$ & $10(45.4)$ \\
\hline \multirow[t]{5}{*}{ No. of AEDs } & 0 & $0(0)$ & $0(0)$ & $8(32.0) *^{\ddagger}$ & $2(6.3)$ & $0(0.0)$ & $0(0.0)$ \\
\hline & 1 & $11(34.4)$ & $9(31.0)$ & $6(24.0)$ & $10(31.3)$ & $5(20.8)$ & $3(13.6)$ \\
\hline & 2 & $5(25.6)$ & $7(24.1)$ & $5(20.0)$ & $9(28.1)$ & $10(41.7)$ & $8(36.4)$ \\
\hline & $>2$ & $16(50.0)$ & $13(44.8)$ & $6(24.0)$ & $11(34.4)$ & $9(37.5)$ & $11(50.0)$ \\
\hline & No & $15(46.9)$ & $24(82.8)$ & $24(96.0)$ & $16(50.0)$ & $14(58.3)$ & $13(59.1)$ \\
\hline Stigma & Yes & $17(53.1)$ & $5(17.2)^{* * \neq}$ & $1(4.0)^{* *}{ }^{\ddagger}$ & $16(50.0)$ & $10(41.7)$ & $9(40.9)$ \\
\hline \multirow[t]{2}{*}{ Anxiety } & No & $14(43.8)$ & $21(72.4)^{* *}{ }^{\dagger}$ & $22(88.0)^{* *}{ }^{\ddagger}$ & $22(68.8)$ & $15(62.5)$ & $14(63.6)$ \\
\hline & Yes & $18(56.3)$ & $8(27.6)$ & $3(12.0)$ & $10(21.3)$ & $9(37.5)$ & $8(36.3)$ \\
\hline \multirow[t]{2}{*}{ Depression } & No & $13(40.6)$ & $20(69.0)^{* *} \dagger^{\dagger}$ & $22(88.0)^{* *} *^{\ddagger}$ & $16(50.0)$ & $13(54.2)$ & $11(50.0)$ \\
\hline & Yes & $19(59.4)$ & $9(31.0)$ & $3(12.0)$ & $16(50.0)$ & $11(45.9)$ & $11(50.0)$ \\
\hline
\end{tabular}

Data are $n(\%)$ values. ${ }^{*} p<0.05$, compared to baseline, ${ }^{* *} p<0.01$, compared to baseline, ${ }^{\dagger} p<0.05$, between surgery and nonsurgery groups, ${ }^{\ddagger} p<0.01$, between surgery and nonsurgery groups. AEDs: antiepileptic drugs

Table 3. Quality of life (QOL) in the surgery and nonsurgery groups

\begin{tabular}{|c|c|c|c|c|c|c|}
\hline & \multicolumn{3}{|c|}{ Surgery group } & \multicolumn{3}{|c|}{ Nonsurgery group } \\
\hline & $\begin{array}{l}\text { Baseline } \\
(n=32)\end{array}$ & $\begin{array}{l}6 \text { months } \\
(n=29)\end{array}$ & $\begin{array}{l}2 \text { years } \\
(n=25)\end{array}$ & $\begin{array}{l}\text { Baseline } \\
(n=32)\end{array}$ & $\begin{array}{c}6 \text { months } \\
(n=24)\end{array}$ & $\begin{array}{c}19 \text { months } \\
(n=22)\end{array}$ \\
\hline Perceived health & $52.0 \pm 10.1$ & $69.2 \pm 16.7^{* *}$ & $74.8 \pm 18.0^{* *}$ & $53.3 \pm 18.0$ & $59.8 \pm 17.7^{*}$ & $57.9 \pm 18.7$ \\
\hline Energy/Fatigue & $40.4 \pm 15.7$ & $62.8 \pm 17.5^{* *}$ & $63.6 \pm 23.1^{* *}$ & $48.2 \pm 19.8$ & $50.4 \pm 25.0$ & $51.1 \pm 24.5$ \\
\hline Overall QOL & $50.0 \pm 14.4$ & $68.8 \pm 13.0^{* *}$ & $65.4 \pm 20.9^{* *}$ & $55.5 \pm 14.0$ & $61.9 \pm 13.8^{*}$ & $62.5 \pm 14.0$ \\
\hline Social functioning & $59.0 \pm 19.6$ & $83.0 \pm 20.4^{* *}$ & $76.7 \pm 30.2^{*}$ & $69.4 \pm 22.4$ & $68.3 \pm 23.6$ & $69.0 \pm 22.8$ \\
\hline Emotional well-being & $45.9 \pm 14.8$ & $65.4 \pm 19.9^{* *}$ & $66.7 \pm 22.4^{* *}$ & $58.9 \pm 18.7$ & $55.2 \pm 24.3$ & $56.4 \pm 24.1$ \\
\hline Cognitive functioning & $62.7 \pm 19.9$ & $72.8 \pm 20.0$ & $66.9 \pm 28.2$ & $55.4 \pm 29.9$ & $51.4 \pm 30.7$ & $50.3 \pm 30.2$ \\
\hline $\begin{array}{l}\text { Role limitations due to } \\
\text { emotional problems }\end{array}$ & $52.8 \pm 37.4$ & $85.6 \pm 26.2^{* *}$ & $98.0 \pm 5.8^{* *}$ & $53.3 \pm 44.8$ & $67.5 \pm 44.5$ & $65.7 \pm 45.7$ \\
\hline $\begin{array}{l}\text { Role limitations due to } \\
\text { memory problems }\end{array}$ & $52.8 \pm 37.8$ & $80.8 \pm 33.4^{*}$ & $86.4 \pm 30.9^{* *}$ & $60.0 \pm 40.8$ & $55.2 \pm 45.2$ & $54.3 \pm 44.5$ \\
\hline $\begin{array}{l}\text { Role limitations due to } \\
\text { physical problems }\end{array}$ & $45.6 \pm 33.4$ & $83.2 \pm 25.6^{* *}$ & $94.8 \pm 20.2^{* *}$ & $48.0 \pm 42.4$ & $50.4 \pm 45.2$ & $51.3 \pm 42.5$ \\
\hline Physical functioning & $83.2 \pm 20.0$ & $93.8 \pm 10.8^{*}$ & $95.8 \pm 14.0^{* *}$ & $79.8 \pm 24.1$ & $86.8 \pm 18.8$ & $87.6 \pm 17.3$ \\
\hline Pain & $53.2 \pm 22.8$ & $85.2 \pm 19.8^{* *}$ & $91.0 \pm 22.4^{* *}$ & $61.0 \pm 26.3$ & $71.5 \pm 23.3^{*}$ & $70.3 \pm 23.1$ \\
\hline $\mathrm{CMH}$ & $50.0 \pm 9.6$ & $69.2 \pm 12.0^{* *}$ & $68.3 \pm 20.4^{* *}$ & $56.5 \pm 14.4$ & $58.0 \pm 18.3$ & $56.1 \pm 16.3$ \\
\hline $\mathrm{CPH}$ & $58.0 \pm 14.6$ & $81.4 \pm 12.4^{*^{\ddagger}}$ & $86.9 \pm 15.9^{* *}{ }^{\ddagger}$ & $60.6 \pm 19.9$ & $67.3 \pm 19.7$ & $68.5 \pm 19.3$ \\
\hline CRF & $54.3 \pm 20.9$ & $81.4 \pm 18.0^{* *}{ }^{\dagger}$ & $85.9 \pm 16.2^{* *}{ }^{\dagger}$ & $55.8 \pm 29.8$ & $60.0 \pm 31.7$ & $59.0 \pm 32.5$ \\
\hline
\end{tabular}

Data are mean $\pm S D$ values. ${ }^{*} p<0.05$, compared to baseline, ${ }^{* *} p<0.01$, compared to baseline, ${ }^{\dagger} p<0.05$, between surgery and nonsurgery groups, ${ }^{\ddagger} p<0.01$, between surgery and nonsurgery groups. $\mathrm{CMH}$ : composite mental health, $\mathrm{CPH}$ : composite physical health, CRF: composite role functioning

The three composite scales did not differ between the two groups at baseline (Table 3), and they were significantly improved at follow-ups at 6 months $($ all $p<0.01)$ and around 2 years $($ all $p<0.01)$ relative to the baseline in the surgery group but not in the nonsurgery group.

The postsurgery scores for the physical-health and rolefunctioning composite measures at 6 months $(p<0.01$ and $p<0.05$, respectively) and around 2 years $(p<0.01$ and $p<0.05$, respectively) were significantly higher in the surgery group than in the nonsurgery group.

\section{Factors related to quality of life in the surgery group}

At the 6-month follow-up, seizure freedom $(p<0.01)$ and the presence of stigma $(p<0.01)$ and anxiety $(p<0.05)$ were related to the mental-health composite measure, whereas economic status $(p<0.05)$ and seizure freedom $(p<0.05)$ were related to the physical-health composite measure. No factors were related to the role-functioning composite measure.

At the 2-year follow-up, the number of AEDs $(p<0.01)$ and the presence of depression $(p<0.01)$, anxiety $(p<0.01)$, and 
stigma $(p<0.01)$ were related to the mental-health composite measure. The number of AEDs $(p<0.05)$ and stigma $(p<0.05)$ were also related to the physical-health composite measure, whereas economic status $(p<0.05)$, number of AEDs $(p<0.01)$, seizure freedom $(p<0.01)$, depression $(p<0.01)$, and anxiety $(p<0.05)$ were related to the role-functioning composite measure.

\section{Discussion}

To our knowledge, this is the first investigation of how the QOL changes over time after epilepsy surgery as compared to presurgery in Korea, and which has included measurement of the QOL in a control nonsurgery group. Although the small sample limits the interpretation of the results, our study also appears to indicate that the factors affecting QOL vary with the follow-up time after surgery.

We collected QOL data at 6 months to avoid the possible confounding effect of surgery, with the results demonstrating that the QOL had improved even at this time after surgery. ${ }^{7}$ One previous study found improvement in the QOL as early as 3 months postsurgery, ${ }^{21}$ whereas others found no such improvement. ${ }^{3,4,12,22,23}$ However, in our study, role functioning was the composite measure that had improved the most at 6 months, which was not evident until 1 year after surgery in previous studies. ${ }^{3,4,12,22,23}$ There are several possible explanations for this discrepancy. Firstly, a marked increase in QOL at 6 months did not appear to be simply due to the passage of time, since the QOL in the nonsurgery group had not improved relative to baseline after 6 months, even though scores on the pain, social-functioning, and health-perception subscales had improved significantly. Rather, it might be related to $86 \%$ of the patients being seizure-free. However, other factors might also have been involved, since the seizure outcome data in our study were comparable to those of the other studies finding no improvement in QOL until 1 year after surgery. ${ }^{3,12}$ Secondly, the decrease in stigma, depression, and anxiety at 6 months that was evident in the surgery group but not in the nonsurgery group might have improved the QOL. ${ }^{24}$ Finally, we cannot rule out the possibility that the lower baseline QOL in our study was due to the sociocultural environment being less favorable in Korea than in Western societies, $9,10,24,25$ with this influencing the marked increase in QOL at 6 months.

We found that the improvement in QOL was not greater at 2 years after surgery than at 6 months after surgery, which is not consistent with previous studies. ${ }^{3,12,26,27}$ However, this might have been related to the significant improvement in QOL that was already present at 6 months (i.e., a ceiling effect). In addition, the patients might also have experienced more burden with the problems of normal life at 2 years, which would have offset any improvement in the QOL resulting from the epilepsy surgery. ${ }^{28}$ The most common expectations for surgery in our patients were obtaining employment or a better job, but they often experienced employment difficulties. Only three of our patients reported that they obtained a better paying job at the 2-year follow-up. However, the QOL did not decrease to the level before surgery, indicating that they had at least maintained their improved QOL during the 2-year postsurgery period.

We found that some patients who were seizure-free after surgery were still experiencing anxiety at the 6-month and 2year follow-ups, which is consistent with previous studies. ${ }^{21,29}$ We suspect that the continuing fear of seizure recurrence in such patients can lower the QOL. Indeed, those patients who experienced anxiety had lower scores on the mental and physical composite QOL scales at the 6-month follow-up.

It is interesting that depression was related to the QOL at the 2-year follow-up but not at the 6-month follow-up. Depression has been reported to be closely related to temporallobe epilepsy. ${ }^{30-32}$ Patients with depression might be inherently predisposed to depression, which could present at 2 years after surgery. The occurrence of mood disturbance as a postsurgery complication is now clearly recognized. ${ }^{11}$ Wilson et al. also reported that psychiatric diagnoses of anxiety and depression were the most frequent reasons for patient readmission after anterior temporal lobectomies. ${ }^{28}$

It is also interesting that the factors important to a high QOL differed between the 6-month and 2-year follow-ups. Although the small sample prevented us from performing a multivariate analysis, seizure freedom was one of important factors related to two of the composite QOL scales at 6 months but not at 2 years, whereas taking more than two AEDs was related to all three composite QOL measures at 2 years but not at 6 months. A negative correlation between the number of AEDs and the QOL has been reported previously. ${ }^{33,34}$ We did not have information regarding the side effects of AEDs in our patients, but it is likely that they experienced difficulties taking the medications and concern over their long-term side effects. ${ }^{35}$ In addition, the cost of AEDs might have constituted an extra burden in their lives. It is also plausible that they did not expect to be continuously medicated with more than two AEDs at 2 years after surgery, especially when they experienced increased seizure freedom.

Our study was subject to some limitations. Firstly, the presurgery measurements of anxiety, depression, and QOL in patients with epilepsy might have been affected by the presence of stress. However, the average time between data collection and surgery was 70 days, and the QOL and the scores on the HAD scale did not differ between the surgery and nonsurgery groups, suggesting that the presurgery environ- 
ment did not affect the presurgery data.

Secondly, sampling bias might have been present since the patients lost at the 2-year follow-up might have experienced seizures with worse characteristics and been less satisfied with the treatment or surgery. However, the patients who were not followed were all seizure-free at 6 months, making it likely that they withdrew after achieving seizure freedom. The good seizure outcome in the surgery group (86\%) suggests that we applied very strict criteria for inclusion. However, the seizure reduction in our study was comparable to that found in previous studies. ${ }^{12,23}$ In addition, the high rate of seizure freedom in the nonsurgery group might have been due to the number of patients referred from other hospitals who were found to be ineligible for surgery but treatable with AEDs. However, regardless of the rate of seizure freedom, the QOL in these patients did not improve significantly at the 6-month follow-up. The rate of seizure freedom in the nonsurgery group was higher than that found in some previous studies $^{6,33}$ but consistent with other studies. ${ }^{26}$

Thirdly, patients with a low economic status who could not afford such an expensive surgical procedure (which was not fully covered by national or private insurance) might have been underrepresented. Therefore, the results obtained here might not be generalizable to all seizure patients. Finally, the two groups we studied were not perfectly matched, since one group qualified for the surgery and one did not, and the second follow-up time differed slightly between the two groups.

In conclusion, the QOL in our population was markedly increased as early as 6 month after epilepsy surgery and was sustained until 2 years postsurgery, trends that are similar to those found in Western countries. However, the factors related to a better QOL differed at each follow-up, with psychological factors being more important than freedom from seizures at 2 years. The small number of patients in our study means that further studies with larger numbers of patients are required to fully clarify these factors.

\section{REFERENCES}

1. Smith D, Baker GA, Jacoby A, Chadwick DW. The contribution of the measurement of seizure severity to quality of life research. Qual Life Res 1995;4:143-158.

2. Kellett MW, Smith DF, Baker GA, Chadwick DW. Quality of life after epilepsy surgery. J Neurol Neurosurg Psychiatry 1997;63:52-58.

3. McLachlan RS, Rose KJ, Derry PA, Bonnar C, Blume WT, Girvin JP. Health-related quality of life and seizure control in temporal lobe epilepsy. Ann Neurol 1997;41:482-489.

4. Selai CE, Elstner K, Trimble MR. Quality of life pre and post epilepsy surgery. Epilepsy Res 2000;38:67-74.

5. Bien CG, Schulze-Bonhage A, Soeder BM, Schramm J, Elger CE, Tiemeier H. Assessment of the long-term effects of epilepsy surgery with three different reference groups. Epilepsia 2006;47:1865-1869.

6. Wiebe S, Blume WT, Girvin JP, Eliasziw M; Effectiveness and Efficiency of Surgery for Temporal Lobe Epilepsy Study Group. A ran- domized, controlled trial of surgery for temporal-lobe epilepsy. $N$ Engl J Med 2001;345:311-318.

7. Spencer SS, Berg AT, Vickery BG, Sperling MR, Bazil CW, Haut S, et al. Health-related quality of life over time since resective epilepsy surgery. Ann Neurol 2007;62:327-334.

8. Tanriverdi T, Olivier NP, Olivier A. Quality of life after extratemporal epilepsy surgery: a prospective clinical study. Clin Neurol Neurosurg 2008;110:30-37.

9. Youn SY, Hong SB. The relationship of stigma and quality of life in patients with epilepsy (Abstract). The Sixth Conference. Korean Epilepsy Society 2001;215.

10. Lee SA, Yoo HJ, Lee BI; Korean QoL in Epilepsy Study Group. Factors contributing to the stigma of epilepsy. Seizure 2005;14:157-163.

11. Derry PA, Rose KJ, McLachlan RS. Moderators of the effect of preoperative emotional adjustment after surgery for temporal lobe epilepsy. Epilepsia 2000;41:177-185.

12. Mikati MA, Comair Y, Ismail R, Faour R, Rahi AC. Effects of epilepsy surgery on quality of life: a controlled study in a Middle Eastern population. Epilepsy Behav 2004;5:72-80.

13. Birbeck GL, Hays RD, Cui X, Vickrey BG. Seizure reduction and quality of life improvements in people with epilepsy. Epilepsia 2002; 43:535-538.

14. Park KA, Kim HS, Kim JS, Kwon SU, Choi-Kwon S. Food intake, frequency, and compliance in stroke patients. Korean J Community Nutr 2001;6:542-552.

15. Zigmond AS, Snaith RP. The hospital anxiety and depression scale. Acta Psychiatr Scand 1983;67:361-370.

16. Oh SM, Min KJ, Park DB. A study on the standardization of the Hospital Anxiety and Depressed Scale for Koreans: a comparison of normal, depressed and anxious groups. J Korean Neuropsychiatr Assoc 1999;38:289-296

17. Jacoby A. Felt versus enacted stigma: a concept revisited. Evidence from a study of people with epilepsy in remission. Soc Sci Med 1994; 38:269-274.

18. Vickrey BG, Hays RD, Graber J, Rausch R, Engel J Jr, Brook RH. A health-related quality of life instrument for patients evaluated for epilepsy surgery. Med Care 1992;30:299-319.

19. Nam BH, Lee SW. Testing the validity of the Korean SF-36 health survey. J Korean Soc Health Stat 2003;28:3-24.

20. Han CW, Lee EJ, Iwaya T, Kataoka H, Kohzuki M. Development of the Korean version of Short-Form 36-Item Health Survey: health related QOL of healthy elderly people and elderly patients in Korea. Tohoku J Exp Med 2004;203:189-194.

21. Spencer SS, Berg AT, Vickrey BG, Sperling MR, Bazil CW, Shinnar $\mathrm{S}$, et al. Initial outcomes in the Multicenter Study of Epilepsy Surgery. Neurology 2003;61:1680-1685.

22. Vickrey BG, Hays RD, Rausch R, Engel J Jr, Visscher BR, Ary CM, et al. Outcomes in 248 patients who had diagnostic evaluations for epilepsy surgery. Lancet 1995;346:1445-1449.

23. O'Donoghue MF, Duncan JS, Sander JW. The subjective handicap of epilepsy. A new approach to measuring treatment outcome. Brain 1998; 121:317-343.

24. Choi-Kwon S, Chung C, Kim H, Lee S, Yoon S, Kho H, et al. Factors affecting the quality of life in patients with epilepsy in Seoul, South Korea. Acta Neurol Scand 2003;108:428-434.

25. Choi-Kwon S, Park KA, Lee HJ, Park MS, Lee CH, Cheon SE, et al. Familiarity with, knowledge of, and attitudes toward epilepsy in residents of Seoul, South Korea. Acta Neurol Scand 2004;110:39-45.

26. Mikati MA, Comair YG, Rahi A. Normalization of quality of life three years after temporal lobectomy: a controlled study. Epilepsia 2006; 47:928-933.

27. Markand ON, Salanova V, Whelihan E, Emsley CL. Health-related quality of life outcome in medically refractory epilepsy treated with anterior temporal lobectomy. Epilepsia 2000;41:749-759.

28. Wilson S, Bladin P, Saling M. The "burden of normality": concepts 
of adjustment after surgery for seizures. J Neurol Neurosurg Psychiatry 2001;70:649-656.

29. Piazzini A, Canevini MP, Maggiori G, Canger R. Depression and anxiety in Patients with Epilepsy. Epilepsy Behav 2001;2:481-489.

30. Blumer D, Wakhlu S, Davies K, Hermann B. Psychiatric outcome of temporal lobectomy for epilepsy: incidence and treatment of psychiatric complications. Epilepsia 1998;39:478-486.

31. Ring HA, Moriarty J, Trimble MR. A prospective study of the early postsurgical psychiatric associations of epilepsy surgery. J Neurol Neurosurg Psychiatry 1998;64:601-604.

32. Quiske A, Helmstaedter C, Lux S, Elger CE. Depression in patients with temporal lobe epilepsy is related to mesial temporal sclerosis. Epi- lepsy Res 2000;39:121-125.

33. Gilliam F, Kuzniecky R, Meador K, Martin R, Sawrie S, Viikinsalo $\mathrm{M}$, et al. Patient-oriented outcome assessment after temporal lobectomy for refractory epilepsy. Neurology 1999;53:687-694.

34. Aydemir N, Ozkara C, Canbeyli R, Tekcan A. Changes in quality of life and self-perspective related to surgery in patients with temporal lobe epilepsy. Epilepsy Behav 2004;5:735-742

35. Pirio Richardson S, Farias ST, Lima AR $3^{\text {rd }}$, Alsaadi TM. Improvement in seizure control and quality of life in medically refractory epilepsy patients converted from polypharmacy to monotherapy. Epilepsy Behav 2004;5:343-347. 